\title{
Konsep Pendidikan Ubudiyah dalam Kitab Sullamut Taufiq Karya Syekh Abdullah bin Husain bin Thohir Ba Alawi
}

\author{
Karimah \\ Institut Dirosat Islamiyah Al-Amien Prenduan, Indonesia \\ karimah@gmail.com
}

\begin{abstract}
Abstrak
Artikel ini berupaya untuk mengungkap konsep pendidikan ubudiyah yang terkandung dalam kitab Sullamut Taufiq Ila Mahabbatillah karya Syekh Abdullah bin Husain bin Thohir Ba Alawi yang merupakan salah satu kitab yang banyak dikaji, dan dikaji di berbagai lembaga dan pesantren yang ada di Indonesia. Untuk mengungkap hal tersebut, peneliti menggunakan penelusuran dan penelaahan literatur serta bahan pustaka lainnya yang relevan dengan masalah yang dikaji, yang meliputi materi-materi yang terdapat dalam kitab Sullamut Taufiq sebagai sumber primer, dan semua tulisan yang berkaitan dengan pendidikan ubudiyah adalah sumber sekunder. Sedangkan teknik analisis data yang penulis tempuh adalah content analysis yang digunakan untuk menarik kesimpulan melalui usaha menemuka karakteristik pesan, dan dikalikan secara objektif dan sistematis. Setelah data terkumpul, kemudian dianalisis dengan menggunakan metode skriptif analisis data. Hasil penelitian ini dapat dipaparkan: pertama yaitu konsep ubudiyah yang meliputi; pengertiannya, macam-macamnya, prinsip-prinsipnya, serta tujuan ubudiyah itu sendiri. Yang kedua yaitu pendidikan ubudiyah yang ada dalam kitab sullamut taufiq yang meliputi perkara yang wajib dikaji dan dilaksanakan oleh setiap orang Islam, seperti shalat, puasa, zakat, haji dan lain sebagainya.
\end{abstract}


Kata Kunci: konsep pendidikan ubudiyah, kitab Sullamut Taufiq

\begin{abstract}
This article seeks to reveal the concept of ubudiyah education contained in the book Sullamut Taufiq Ila Mahabbatillah by Sheikh Abdullah bin Husain bin Thohir Ba Alawi which is one of the books that is widely recited, and studied in various institutions and Islamic boarding schools in Indonesia. To reveal this, the author uses literature search and review and other library materials that are relevant to the problem being studied, which includes materials contained in the book of Sullamut Taufiq as primary sources, and all writings related to ubudiyah education are secondary sources. While the data analysis technique that the author uses is content analysis which is used to draw conclusions through efforts to find the characteristics of the message, and multiply it objectively and systematically. After the data was collected, it was then analyzed using a descriptive data analysis method. The results of this research can be described: first, namely the concept of ubudiyah which includes; its meaning, kinds, principles, and objectives of ubudiyah itself. The second is ubudiyah education contained in the book of Sullamut Taufiq which includes matters that must be studied and carried out by every Muslim, such as prayer, fasting, zakat, hajj and so on.
\end{abstract}

Keywords: ubudiyah education concept, book of sullamut taufiq

\title{
PENDAHULUAN
}

Ubudiyah dalam segi bahasa diambil dari kata ibadah yaitu menunaikan perintah Allah dalam kehidupan sehari-hari dengan melaksanakan tanggung jawab sebagai hamba Allah. ${ }^{1}$

Dalam Syari'at Islam ibadah mempunyai dua unsur, yaitu ketundukan dan kecintaan yang paling dalam kepada Allah Swt. Unsur yang tertinggi adalah ketundukan, sedangkan kecintaan

\footnotetext{
1 Fathullah Gulen, Kunci Rahasia Sufi (Jakarta: PT. Raja Grafindo-Persada, 2001), 95.
} 
merupakan implementasi dari ibadah tersebut. di samping itu ibadah (ubudiyah) juga mengandung unsur kehinaan, yaitu kehinaan yang paling rendah di hadapan Allah Swt, pada mulanya ibadah merupakan "hubungan" karena adanya hubungan hati dengan yang dicintai menenangkan isi hati kemudian tenggelam dan merasakan keasyikan, akhirnya sampai kepada puncak kecintaan kepada Allah Swt. ${ }^{2}$

Ada tiga bentuk ibadah menurut ahli tasawwuf, pertama ibadah kepada Allah Swt karena sangat harap memperoleh pahalanya atau karena takut atas siksanya, kedua ibadah kepada Allah Swt karena memandang bahwa ibadah itu perbuatan muliya dilakukan oleh orang yang muliya jiwanya, ketiga ibadah kepada Allah Swt karena memandang bahwa Allah Swt berhak disembah dengan tidak memperhatikan apa yang akan diterima atau diperoleh dari padanya. ${ }^{3}$

Dengan demikian, manusia itu diciptakan bukan sekedar untuk hidup mendiami dunia ini dan kemudian mengalami kematian tanpa adanya pertanggung jawaban kepada penciptanya, melainkan manusia itu diciptakan oleh Allah Swt untuk mengabdi kepadanya. ${ }^{4} \mathrm{Hal}$ ini dinyatakan dalam Al-Qur'an Surat Al-Bayyinah (98):5:

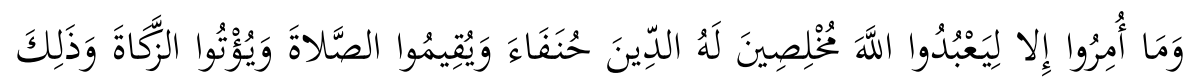
دِينُ الََْيْمَةِة (0)

\footnotetext{
2 Rahman Ritonga dan Zainuddin, Fiqh Ibadah (Jakarta: Gaya Media Pratama, 1997), 4.

3 Ibid., 3.

${ }^{4}$ Ahmad Thib Raya dan Siti Mulia, Menyelami Seluk Beluk Ibadah dalam Islam (Jakarta: Prenada Media, 2003), 139.
} 
Artinya: Padahal mereka tidak disuruh kecuali supaya menyembah Allah dengan memurnikan ketaatan kepadanya dalam (menjalankan) agama dengan lurus. (QS.Al-Bayyinah. 5) 5

Oleh sebab itu sebagai seorang hamba yang telah diciptakan oleh Allah Swt, manusia seharusnya bersyukur bukan hanya dengan mengucap Al-Hamdalah saja melainkan manusia harus tunduk dan patuh terhadap apa yang diperintahkan oleh Allah dan menjauhi segala larangannya dengan kata lain kewajiban seorang mukallaf (dewasa) ialah melaksanakan segala perkara yang diwajibkan sesuai aturan yang telah Allah perintahkan dan menjahui segala perkara yang diharamkannya. ${ }^{6}$

Perintah dan larangan Allah tidak akan terlaksana dengan benar jika seorang hamba tidak memiliki ilmu pengetahuan, ilmu pengetahuaan tidak akan diperoleh manusia kecuali melalui pengajaran atau pendidikan. Karena dengan melalui pendidikan Manusia akan mengetahui tentang bagaimana tatacara beribadah yang baik dan benar sesuai dengan yang telah dianjurkan oleh Allah Swt.

Pendidikan ubudiyah itu sendiri banyak terdapat diberbagai kitab akan tetapi peneliti lebih tertarik kapada pengkajian kitab sullamut taufiq karena sejauh yang peneliti telusuri kitab sullamut taufiq adalah kitab klasik yang populer dikaji diberbagai lembaga Madrasah dan Pesantren.

Dalam kitab sullamut taufiq selain menerangkan tentang ubudiyah juga menerangkan tentang sifat-sifat Allah dan

\footnotetext{
${ }^{5}$ Enang Sudrajad, Al-Qur'an dan Terjemahnya (Jakarta: PT. Hati Emas, 2007), 598.

${ }^{6}$ Syekh Nawawi, Sullamut Taufiq Berikut Penjelasannya, terj. Moch Anwar dan Anwar Abu Bakar (Bandung: Sinar Baru Algensindo, 2015), 32.
} 
Rasulnya, tentang murtad dan hukumnya, tentang macam-macam maksiat serta mengenai taubat. Dan lain sebagainya Sesuai perkataan syekh Abdullah bin Husain bin Thohir Ba Alawi dalam muqoddimah kitab Sullamut Taufiq yang menerangkan bahwa" Sullamut Taufiq Ila Mahabbatillah 'Alat Tahqiq merupakan kitab kecil yang pelik, yang menerangkan perkara yang wajib dikaji dan dipelajari serta diamalkan bagi orang yang mengerti maupun yang belum memahaminya sebagaimana artinya yang merupakan tangga pertolongan untuk mencintai Allah sebenar-benarnya". ${ }^{7}$

Kitab Sullamut Taufiq juga membahas tentang hukum Islam, yakni tentang wajib dan haram. Perkara yang wajib dikerjakan oleh umat muslim dalam naskah ada 20, yang meliputi 1) kewajiban mengucap kalimat syahadat; 2) kewajiban menjaga agama; 3) kewajiban orang murtad; 4) kewajiban orang mukallaf; 5) waktu salat; 6) kewajiban salat; 7) syarat-syarat salat; 8) istinjak; 9) fardhunya mandi; 10) syarat-syarat bersuci; 11) mencuci najis; 12) menutup aurat; 13) khusuk dalam salat; 14) salat Jumat; 15) kewajiban terhadap mayit; 16) harta yang wajib dizakati; 17) puasa Ramadhan; 18) ibadah Haji; 19) kewajiban memberi nafkah; dan 20) kewajiban setiap mukmin. Sedangkan perkara yang haram dilaksanakan oleh umat muslim ada 3, yakni 1) larangan bagi yang batal wudhu; 2) larangan riba; dan 3) macam-macam riba. ${ }^{8}$

\footnotetext{
7 Syekh Abdullah bin Husain Ba Alawi, Sullamut Taufiq, terj. Abdul Halim (Surabaya: Maktabatil Hidayah, t.t.), 2.

8 Citra Nur Arini, "Hukum Islam Dalam Naskah Sullam Taufiq (Kajian Filologis)," Bapala, vol.1, no. 1 (2018): 1-19.
} 
Kajian tentang pendidikan tauhid dalam kitab Sullamut Taufiq dilakukan oleh Muhammad Azis Fuad ${ }^{9}$ menyebutkan bahwa pertama, nilai ilahiyah yang mencakup interpretasi iman, Islam, ihsan, takwa, sabar, tawakal, syukur, ikhlas dan taubat. Kedua, nilai insaniyah mencakup interpretasi husnudhdhon, jujur, menjaga lisan, silaturahmi, tawadu', amanah, ukhuwah, dan adil. Sedangkan relevansi nilai-nilai pendidikan tauhid dalam kitab Sullam At-Taufiq dengan pendidikan Indonesia dapat dilihat dari pertama, terdapat relevansi antara tujuan pendidikan nasional dan pancasila sila pertama dengan mengawali penanaman tauhid setiap manusia dengan meyakini dan mahami sifat-sifat Allah dan Rasul-Nya, kedua relevansi antara kewajiban orang Islam menjaga Islamnya dengan kewajiban peserta didik menjaga norma-norma pendidikan untuk keberhasilan pendidikan, dan ketiga, relevansi antara perhatian guru kepada semua peserta didik tanpa diskriminasi dengan kecintaan pengarang kitab kepada semua orang termasuk orang yang telah murtad.

\section{METODE PENELITIAN}

Penelitian ini menggunakan pendekatan kualitatif jenis penelitian kepustakaan atau library research. Sumber data primer dalam penelitian ini adalah kitab Sullamut Taufiq Ila Mahabbatillah Alat Tahqiq karya Syekh Abdullah bin Husain bin

\footnotetext{
${ }^{9}$ Muhammad Azis Fuad, "Nilai-Nilai Pendidikan Tauhid Dalam Kitab Sullam AtTaufiq Karya Syaikh Sayyid Abdullah Bin Husain Bin Thahir" (other, IAIN SALATIGA, 2018), diakses 17 Desember 2018, http://erepository.perpus.iainsalatiga.ac.id/4252/.
} 
Thohir Ba Alawi. Adapun dalam pengumpulan datanya, penulis membatasi kajian pada materi-materi yang terdapat dalam kitab Sullamut Taufiq sebagai sumber primer, dan semua tulisan yang berkaitan dengan pendidikan ubudiyah adalah sumber sekunder.

Sedangkan teknik analisis data yang penulis tempuh adalah content analysis yang digunakan untuk menarik kesimpulan melalui usaha menemukan karakteristik pesan, dan dikalikan secara objektif dan sistematis. Setelah data terkumpul, kemudian dianalisis dengan menggunakan metode skriptif analisis data.

\section{HASIL DAN PEMBAHASAN \\ Profil Kitab Sullamut Taufiq}

Penulis Kitab Sullamut Taufiq bernama Al-Alamah Syekh Abdullah bin Al-Husain bin Thahir bin Muhammad bin Hasyim Ba Alawi Al-Hadhrami adalah seorang ulama yang dikenal sebagai ahli ilmu fiqih yang bermadzhab Syafi'i dan sekaligus ahli ilmu nahwu. Beliau dilahirkan di Tarim, Hadhramaut, Yaman pada tahun 1191-1272 $\mathrm{H}$ atau bertepatan dengan tahun 1778-1855 M. Beliau pernah mukim beberapa tahun di mekah dan Madinah dan belajar kepada beberapa ulama yang masyhur disana. ${ }^{10}$

Setelah beberapa tahun di mekah dan Madinah beliau kembali ke negaranya dan bermukim di Masilah, satu daerah yang terletak disebelah selatan kota tarim. Setelah kembali ke negaranya, beliau mengabdikan dirinya untuk memberikan

10 Khoiruddin Az-Zirikli, Al - A'aam Qamus Tarajim Li Asyharir Rijal Wan Nisa'Minal Arab Wal Musta'ribin WI Mustasyriqin (Beirut: Darul Ilmi Lil Malayin, 2002), 81. 
ceramah dan mengajarkan ilmu-ilmu agama dan mengisi waktuwaktunya untuk beribadah. ${ }^{11}$

Syekh Abdullah adalah seorang pakar Fiqh, penyair handal (syua'ra') sekaligus pakar Nahwu Shorof (sintaksis-morfologis). seorang yang produktif menulis diantara karya-karya beliau adalah: Sullam al-Taufiq, Miftahul I'rab, Majmu'atur Rasail, Wasiah al-Kubra, al-Ahdul Majhud fi wasiyatil Junud, al-Ifadah bi ta'rif al-adah, al-Ahadis a-jamiah, Tadzkirah al-Mu'minin, Nasihah al-Mu'minin. ${ }^{12}$

Sullam al-Taufiq mendapat banyak apresiasi dari ulama dengan menulis komentar (syarh) seperti Mirqatu Shu'ud alTashdiq buah karya Syaikh Nawawi al-Bantani, juga Is'adur Rafiq Wa Bughyah al-Shiddiq oleh Muhammad Bin Salim Bin Sa'id Ba Bashil Al-Syafi'i. Di samping komentar (syarh), kitab Sullam alTaufiq menginspirasi sebuah karya dalam bentuk prosa sebanyak 500 bait karya KH. Abdul Hamid Pasuruan dengan judul Mandzumah Sullamut Taufiq. Selain komentar (syarh), prosa (nadhom) juga terdapat karya yang merupakan ringkasan (ihtishar), yaitu Mukhtashar Abdullah Al-Harori al-Kafil bi Ilmi al-Din Al-Dharuri yang di tulis oleh Syaikh Abdullah Al-Harori.

Semasa hidupnya beliau telah menulis beberapa kitab, diantaranya adalah" Sullamut Taufiq Ila Mahabbatillah Alat tahqiq" dan "Miftahul I' rob". Beliau wafat pada bulan Robi'ul awwal tahun 1242 H.Murid beliau, Al-Habib Al-Idrus bin Umar bercerita bahwa setiap hari gurunya membaca "Laa Ilaa ha

\footnotetext{
${ }^{11}$ Syekh Abdullah Al-harari, Umdatur Roghib Fi Mukhtashor Bughyatut Tholib, t.t., 10 .

12 Abdullah bin muhammad Al-Saqqah, Tarikh Al-Hadramiyyin, 3 ed. (Mesir: Matba'ah Hijazi, 1353), 162-177.
} 
Illalloh' sebanyak 25.000 kali, membaca "Ya Alloh" sebanyak 25.000 kali dan membaca sholawat juga sebanyak 25.000 kali. Selain itu setiap akan mengerjakan sholat fardhu beliau mandi dan memakai minyak wangi. 13

Di antara petuah-petuah beliau: "Bagi orang yang berdakwah, mengajak orang lain mengerjakan kebaikan dan mencegah meningalkan kemungkaran (amar ma'ruf nahi munkar) hendaknya bersikap lembut dan belas kasih pada semua orang. Mengajak mereka sedikit demi sedikit, dan apabila melihat mereka meninggalkan kewajiban maka suruh mereka untuk mengerjakan yang paling penting dari kewajibankewajiban tersebut, jika mereka mengerjakanya barulah suruh untuk mengerjakan yang lainya. 14

Ajak mereka mengerjakan kebaikan dan takut-takuti agar tidak meninggalkan kewajiban atau melakukan kemunkaran. Namun lakukan semua itu dengan lembut dan belas kasih, dan tanpa memandang apakah mereka memuji atau mencela, mereka memberikan sesuatu atau tidak memberikan apa-apa, sebab jika sampai orang yang berdakwah semua itu maka ia akan melakukan segala sesuatu dengan tujuan mudahanah (cari muka).

Dan apabila mereka melakukan banyak hal yang dilarang oleh agama dan tidak mengubris larangan-larangan agama, maka beri tahu mereka tentang larangan-larangan tersebut

\footnotetext{
${ }^{13}$ Al-harari, Umdatur Roghib Fi Mukhtashor Bughyatut Tholib, 10.

14 Ibid.
} 
sebagiannya saja, lalu lain kali beritahu larangan-larangan lainya dan begitu pula seterusnya. ${ }^{15}$

Dalam Kitab ini Syekh Abdullah bin Husain bin Thohir Ba Alawi menyebutkan bahwa karyanya ini merupakan buku yang mengetengahkan ilmu-ilmu yang wajib dipelajari, diajarkan serta diamalkan bagi yang mengerti maupun yang belum memahaminya. Baru setelah mereka mampu untuk melakukan hal-hal yang wajib, mereka akan dengan senang hati melakukan hal-hal yang bersifat sunnah, sehingga akhirnya mereka mampu benar-benar menggapai cinta Allah dan mendapat pertolongannya. 16

\section{Konsep Pendidikan Ubudiyah dalam Kitab Sullamut Taufiq}

Konsep Pendidikan ubudiyah (ibadah) yang terdapat dalam kitab Sullamut Taufiq secara keseluruhan dapat diklasifikasikan menjadi ibadah umum dan ibadah khusus. Ibadah umum mempunyai ruang lingkup yang sangat luas, yaitu mencakup segala amal kebajikan yang dilakukan dengan niat ikhlas dan sulit untuk mengemukakan sistematikanya. Oleh sebab itu dalam penelitian ini penulis memfokuskan kepada ibadah khusus saja karena ibadah khusus telah ditentukan oleh syara' (Nash) bentuk dan caranya, dan dapat dikemukakan sistematikanya secara garis besar. Yang meliputi: thaharah, shalat puasa, zakat, haji dan lain sebagainya.

Sedangkan pendidikan ubudiyah (ibadah) khusus yang ada dalam kitab sullamut taufiq yaitu meliputi tentang kewajiban-

15 Ibid.

${ }^{16}$ Syekh Abdullah bin Husain Ba Alawi, Sullamut Taufiq, 2. 
kewajiban setiap orang Islam baik itu laki-laki maupun perempuan kepada Allah Swt sebagai berikut: tentang thaharah, shalat, zakat, puasa, haji, sebagaimana yang telah penulis paparkan di atas.

Konsep pendidikan ubudiyah tersebut sama dengan konsep pendidikan yang ada dalam kitab-kitab yang lain seperti halnya yang ada dalam kitab Safinatun Najah. Peneliti memilih kitab Safinatun Najah karena menurut penulis kitab tersebut cocok untuk dibandingkan dengan kitab Sullamut Taufiq dengan alasan:

1. Dalam pembahasannya sama-sama berorientasi pada masalah pokok-pokok agama Islam secara terpadu

2. keduanya disajikan dengan bahasa yang mudah, susunannya yang ringkas dan redaksi yang tidak sulit untuk dipahami

3. Sama-sama diperuntukkan untuk golongan siapa saja terlebih kepada para pemula

4. Sama-sama bermadzhab Syafi'ie

5. Sama-sama membicarakan hal-hal yang menjadi kebutuhan seorang muslim dalam kehidupan sehari, sehingga semua orang merasa perlu untuk mempelajarinya

6. Sama-sama telah banyak diterjemahkan dalam berbagai bahasa, seperti; indonesia, madura, sunda, melayu dan lain sebagainya.

Kedua kitab tersebut, selain memiliki kesamaan juga terdapat perbedaan dalam sistematika pembahasannya seperti halnya dalam pembahasannya. Seperti:

1. Tentang thaharah, dalam kitab Sullamut Taufiq Syekh Abdullah hanya membahas tentang wudhu, hadats dan istinja. Sedangkan di dalam kitab Safinatun Najah pembahasan 
mengenai thaharah lebih diperluas, didalam kitab tersebut selain membahas tentang whudhu, hadast dan istinja syekh Salim menjelaskan tentang macam-macam air, dan macammacam najis. ${ }^{17}$

2. Juga tentang hal-hal yang mewajibkan, dalam kitab Sullamut Taufiq hal-hal yang mewajibkan mandi itu ada 5, yaitu; keluar mani, bersetubuh, keluar darah haid, keluar darah nifas, dan melahirkan, sedangkan dalam kitab safinatun naja dijelaskan bahwa hal-hal yang mewajibkan mandi ada enam, yaitu: memasukkan kemaluan (kepala dzakar) ke dalam farji (kemaluan) perempuan, keluar air mani. keluar darah haidh (datang bulan), keluar darah nifas (darah yang keluar setelah melahirkan), melahirkan, dan yang ke enam yaitu mati selain mati syahid. 18

3. Dalam kitab Safinatun Najah juga menjelaskan tentang masalah tayammum sedangkan dalam kitab Sullamut Taufiq tidak ada pembahasan mengenai tayammum.

4. Tentang shalat, dalam kitab Safinatun Najah ada keterangan dibolehkan meringkas shalat bagi orang musafir seperti shalat dhuhur diringkas menjadi dua rakaat, sedangkan dalam kitab Sullamut Taufiq tidak ada bahasan seperti itu.

Dengan demikian, maka terdapat perbedaan antara konsep pendidikan ubudiyah dalam kitab Sullamut Taufiq dengan konsep pendidikan ubudiyah yang terdapat dalam kitab Safinatun Najah yang meliputi dalam pembahasan tentang ubudiyah khusus kitab

\footnotetext{
17 Syakh Salim bin Sumair Al-Hadhrami, Safinatun Najah, terj. Muhammad Nur Munir (Surabaya, t.t.), 5.

18 Ibid.
} 
Safinatun Najah lebih luas dibandingkan dengan pendidikan ubudiyah khusus yang ada dalam kitab Safinatun Najah. Hal ini mungkin disebabkan karena dalam kitab Sullamut Taufiq cakupan pembahasannya tentang Trilogi keilmuan yang meliputi: ilmu taihid, ilmu fiqih dan ilmu tasawwuf sedangkan dalam kitab Safinatun Najah tidak membahas tentang ilmu tasawwuf walaupun sama-sama membahas tentang pokok-pokok ajaran Islam yang selalu menjadi kebutuhan seorang muslim dalam kehidupan sehari-hari, sehingga semua orang merasa perlu untuk mempelajarinya.

\section{KESIMPULAN}

Konsep Pendidikan ubudiyah yang ada dalam kitab Sullamut Taufiq merupakan ibadah yang penting dikaji dan dilaksanakan oleh setiap orang Islam baik laki-laki maupun perempuan karena dalam kitab tersebut membahas tentang perkara yang wajib, tidak membahas tentang perkara yang disunnahkan. Oleh sebab itu kitab Sullamut Taufiq sangat cocok dikaji oleh siapa saja.

Konsep pendidikan ubudiyah dalam kitab Sullamut Taufiq secara keseluruhan dapat diklasifikasikan menjadi dua, yaitu: Pertama, ibadah umum, yaitu ibadah yang mempunyai ruang lingkup yang sangat luas, mencakup segala amal kebajikan yang dilakukan dengan niat ikhlas dan sulit untuk mengemukakan sistematikanya. ibadah khusus, yaitu ibadah yang telah ditentukan oleh syarak (Nash) bentuk dan caranya, dan dapat dikemukakan sistematikanya secara garis besar. 
Sedangkan pendidikan ubudiyah (ibadah) khusus yang ada dalam kitab Sullamut Taufiq yaitu meliputi tentang kewajibankewajiban setiap orang Islam kepada Allah Swt sebagai berikut: tentang Thaharah yang meliputi: wudhu, hadats dan bersuci (istinja'), tentang Shalat Fardhu yang meliputi: waktunya, syaratsyaratnya, hal-hal yang membatalkannya, rukunnya, shalat berjamaah jum'at khusus kepada laki-laki. tentang Zakat, Puasa dan hal-hal yang membatalkannya, dan Haji.

\section{DAFTAR PUSTAKA}

Al-Hadhrami, Syakh Salim bin Sumair. Safinatun Najah. terj. Muhammad Nur Munir. Surabaya, t.t.

Al-harari, Syekh Abdullah. Umdatur Roghib Fi Mukhtashor Bughyatut Tholib, t.t.

Al-Saqqah, Abdullah bin muhammad. Tarikh Al-Hadramiyyin. 3 ed. Mesir: Matba'ah Hijazi, 1353.

Arini, Citra Nur. "Hukum Islam Dalam Naskah Sullam Taufiq (Kajian Filologis).” Bapala, vol.1, no. 1 (2018): 1-19.

Az-Zirikli, Khoiruddin. Al - A'aam Qamus Tarajim Li Asyharir Rijal Wan Nisa'Minal Arab Wal Musta'ribin WI Mustasyriqin. Beirut: Darul Ilmi Lil Malayin, 2002.

Fuad, Muhammad Azis. "Nilai-Nilai Pendidikan Tauhid Dalam Kitab Sullam At-Taufiq Karya Syaikh Sayyid Abdullah Bin Husain Bin Thahir." Other, IAIN SALATIGA, 2018. Diakses $17 \quad$ Desember 2018.2 http://erepository.perpus.iainsalatiga.ac.id/4252/.

Gulen, Fathullah. Kunci Rahasia Sufi. Jakarta: PT. Raja GrafindoPersada, 2001.

Nawawi, Syekh. Sullamut Taufiq Berikut Penjelasannya. terj. Moch Anwar dan Anwar Abu Bakar. Bandung: Sinar Baru Algensindo, 2015.

Raya, Ahmad Thib, dan Siti Mulia. Menyelami Seluk Beluk Ibadah dalam Islam. Jakarta: Prenada Media, 2003.

Ritonga, Rahman, dan Zainuddin. Fiqh Ibadah. Jakarta: Gaya Media Pratama, 1997.

Sudrajad, Enang. Al-Qur'an dan Terjemahnya. Jakarta: PT. Hati Emas, 2007. 
Syekh Abdullah bin Husain Ba Alawi. Sullamut Taufiq. terj. Abdul Halim. Surabaya: Maktabatil Hidayah, t.t. 
Karimah | MAHAROT Vol. 4 No. 1, 2020 